\title{
The Framework of the Civil Servants' Education in the Conditions of Sustainable Development of the Republic of Belarus
}

\author{
Irina Sidorchuk ${ }^{1}$, Aleksei Akhrymenka ${ }^{2}$, Volha Basko ${ }^{3}$, Alexei Grigoriev ${ }^{4}$ and \\ Anton Parfenchyk ${ }^{5}$
}

\begin{abstract}
Achieving the goals of sustainable development largely depends on the state machinery effectiveness and the professionalism of civil servants. Continuous education (life-long training) is an effective tool for ensuring competence level of civil servants. According to the results of the analysis of the education system of civil servants, it can be argued that in the Republic of Belarus it has developed a mixed framework of education for civil servants, which is characterized by a combination of innovative and traditional forms and teaching methods aimed at their professional and personal development. The training of civil servants is carried out within the annual governmental order. The existing educational framework was developed before the adoption of the 2030 Agenda, in this regard, the education of public servants does not fully take into account the paradigm of sustainable development. The solution is seen in the transition from the annual government order for training of civil servants to long-term, medium-term and short-term planning of their training, which correlates with the Sustainable Development Goals. It is also important to implement the principle of inclusion in education. This will entail not only the improvement of the scientific and methodological support of the educational process and the creation of new educational programs, but also an increase in the requirements for the level of teachers training and the intensification of the students role. We also believe that the use of advanced foreign experience in the learning process will strengthen the personnel capacity of the state machinery and promptly implement changes to reflect the new realities. The listed aspects of the civil servants education framework transformation in the Republic of Belarus can become potential growth points that in the long term will allow Belarus to achieve the Sustainable Development Goals.
\end{abstract}

\section{Introduction}

Practical implementation of the sustainable development concept provides a universal algorithm for long-term success and balanced life of the society of modern states. Traditional governmental functions are no longer able to ensure the security and development of society, the welfare of its citizens. Achieving harmonious relations in the triad "man - environment - economy" determine filling these functions with the content of sustainable development goals taking into account national realities, strategies and priorities, opportunities and the level of development of a particular country.

\footnotetext{
${ }^{1}$ The Institute of Information Technologies, Belarusian State University of Informatics and Radioelectronics ${ }^{2}$ Director of the Institute of Information Technologies, Belarusian State University of Informatics and Radioelectronics, Minsk, Belarus

${ }^{3}$ Leading Specialist at the Information and Analytical Support Department of the AIS "Reserve" at the AIS "Reserve" Support Center, the Academy of Public Administration under the aegis of the President of the Republic of Belarus

${ }^{4}$ Director of Legal and Human Resources Department of the State Supervisory Department for Telecommunications of the Republic of Belarus

${ }^{5}$ Researcher at the Section of Research in the Field of State Organization and Society Development, International Law at the Institute for Legal Research, the National Centre of Legislation and Legal Research of the Republic of Belarus, Minsk, Belarus
} 
The effective state machinery activity in implementing the sustainable development strategy directly depends on the professionalism of civil servants at all levels of government, their adequate understanding of the sustainable development paradigm. Modern realities are such that from civil servants it is required to be active subjects of occurring changes, be able to generate innovations, develop and implement large-scale projects. The growth of the requirements to the level of competencies of civil servants, in turn, creates increased requirements for their training system.

According to "the National Strategy for Sustainable Social and Economic Development of the Republic of Belarus until 2030" (hereinafter - NSSSED 2030) education is given the leading role in improving the quality of human potential. It is indicated that the training of educated and highly qualified people is a strategic goal, the achievement of which will enable the Belarusian economy to gain a competitive advantage. It was also noted that the educational system should ensure that the acquired knowledge and skills meet the rapidly changing requirements of society and the economy, technology, the development of personal initiative and adaptability of the person, thanks to which his opportunities to integrate ideas and innovations are expanded.

Earlier in scientific literature on sustainable development there were studied transformations of the European public administration systems in terms of achieving such objectives as sustainable development (Berceanu \& Carausan, 2014, p. 26), the development of teaching, learning and assessment contents within sustainable context (Viertel, 2010, p. 231), including management programmes (Hailey, 1998, p. 40; Fukukawa, Spicer, Burrows, \& Fairbrass, 2013, p. 71). M. Terlević, A. Istenič Starčič and M. Šubic Kovač affirms that education for sustainable spatial development includes multiple aspects, therefore it is necessary to transform some of the academic programs taking into account interdisciplinary integration. (2015). F. Annan-Diab and C. Molinari also demonstrates the importance of an interdisciplinary approach to education for sustainable development (2017, p. 73).

Despite the importance of the civil servants in sustainable development, as well as the role of education in the NSSSED 2030, the issue of adjusting the framework of the civil servants' education in the context of transition to sustainable development has not received sufficient attention before.

The commitment of Belarus to the achievement of sustainable development goals (hereinafter - SDG) was certified by the Head of State by signing the 2030 Agenda for Sustainable Development (hereinafter - 2030 Agenda) at the UN summit. The approaches to achieving the SDG are reflected in two main Belarusian documents: NSSSED 2030 key program document defining the main directions of development and "the Social and Economic Development Program for 2016-2020”. In accordance with these documents, the strategy of sustainable development is to ensure high living standards of the population and conditions for the harmonious development of the individual within the transition to a highly efficient economy based on knowledge and innovation, while maintaining a favorable environment for present and future generations.

In addition to the legal framework SDG implementation, in Belarus have been taken organizational measures. In particular, the President of the Republic of Belarus has appointed the National Coordinator for the SDG achievement, and the Council for Sustainable Development has been formed. The Council for Sustainable Development 
includes representatives from public authorities at the level of deputy heads. Representatives of business circles, public associations, and international organizations are invited to participate in the mentioned council. The National Coordinator for the organizes the discussion of SDG implementation within the Council for Sustainable Development and will report annually on the progress of the SDG implementation to the President of the Republic of Belarus and the Government of the Republic of Belarus, as well as makes recommendations for improving the effectiveness of this activity.

However, significant work remains to be done, both to inform the various social groups about the content and significance of the SDG, and to process of SDG implementation. At the same time, civil servants play a key role in the implementation of the sustainable development, they are the vehicles of public decisions. M. Rybasova and Z. Razhabova argue that the government must be both the main subject and the instrument that ensures the transition to sustainable development (2014, p. 69). It is intended to create a balanced system that can align the economic and social interests of society. Therefore, it is necessary to information key stakeholders about SDG and its main components.

Only effective and future-oriented education system can prepare highly educated, able to receive and creative civil servants that are required by the modern economy. In this regard, the urgent task is the consistent alignment of such a framework of advanced education, which will be able to provide timely responses to changes occurring in all spheres of human activity. First and foremost, this is necessary for the field of civil servants training. Civil servants in their essence are the subjects of transformations taking place in society.

In the Republic of Belarus, integrating the ideas and principles of sustainable development into the education sector will allow the SDG to be viewed as one of the key elements of the civil service education framework, along with traditional elements such as the legal and organizational foundations, including laws and regulations, policies, methods, professors, students, facilities, etc.

In order to achieve SDG the framework of the civil servants' education could be transformed according to the figure 1. The transformation of the educational framework could mobilize the internal resources in terms of sustainable development.
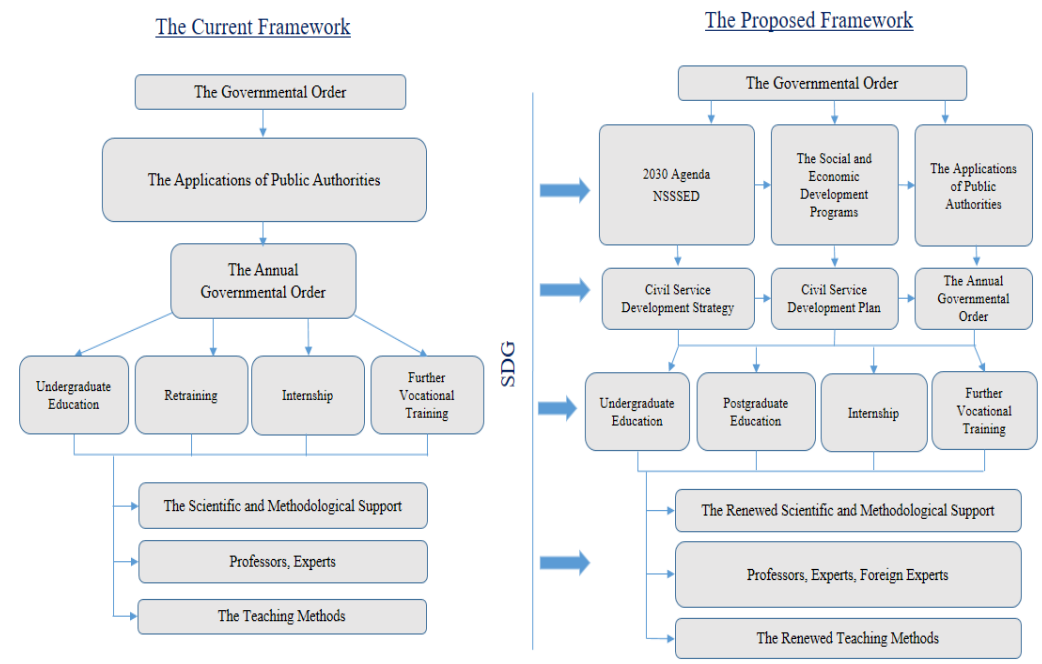

Figure 1: The Transformation of the Framework of the Civil Servants' Education in the Conditions of Sustainable Development of the Republic of Belarus 
The following is devoted to the details of the perspective framework.

The governmental order occupies the leading place in the field of civil servants' training in Belarus which is developed annually. The main documents that regulates the civil servants' education are Presidential Decree "On some measures to improve the education, internship and further vocational training of personnel in the field of public administration", June 2, 2009, and the Presidential Decree "On work with leading cadres in the public authorities' system", July 26, 2004. These documents are foundation for the continually acquire knowledge by civil servants and managers of the state-owned corporates in the field of public administration, economics, law and leadership. It is also legally enshrined that the principles of systemic, scientific, prospective and differential approach are the main ones in ensuring the learning process.

The analysis shows that the SDG are not fully integrated into the legislation. The only exception is the the Presidential Decree "On work with leading cadres in the public authorities' system" which consist the thesis that presence of a prepared reserve is considered as the most important condition for the continuity of leading cadres, improving the efficiency of public administration, ensuring sustainable social and economic development of the nation.

The NSSSED 2030 specifies that, in order to ensure the availability of quality education that meets the requirements of sustainable development, by 2020 the quality of the educational process should be increased taking into account the principles of sustainable development. This involves upgrading the skills of civil servants in environmental security, sustainable regional development, etc. Besides, according to the new educational framework, the role of public authorities is increasing.

At present, the primary task is to make more systematic civil servants' training that includes improvement of the cross-agencies coordination in the field of the civil servants' professional development. For this, not only the nearest (short-term) goal should be formulated, but also medium-term and long-term prospects.

In the long term, the system of views on the development of the human resources capacity of public administration is determined by the Civil Service Personnel Policy of the Republic of Belarus Concept, approved by the Presidential Decree. The mentioned concept contains priorities of the civil service personnel policies and the mechanism for its implementation. Among the priorities of public administration is the creation of a system for forecasting and planning the staffing needs of public authorities, as well as the development of special curriculum.

The main forecast of the Belarusian socio-economic development for the medium term is approved as the Social and Economic Development Program for 2016-2020. In the document number of measures aimed at strengthening the effectiveness of public administration, indicated the increased professionalism of civil servants, which is planned to be implemented through the training (internship) in the world's leading educational institutions, as well as training of civil servants for fluency in foreign languages.

Other regulations relate to the civil servants' professional developments needs among which, for example, the Plan of Measures for the Legal Education of Citizens for 20162020 indicating that lawyers of public authorities should be regularly trained. Also it is necessary to note the regional programs 'Cadres', which were adopted at the beginning of the 2010s and acted in 2011-2015. The programs contained a number of provisions 
relating to forecasting the development of the human resources capacity of local executive and regulatory bodies in the medium term. However, the mentioned regional programs were not extended for a new period.

Thus, there are no plans and strategies for civil servants' professional development in the medium term both at the national and local levels. The documents aimed at the longterm perspective were adopted more than fifteen years ago, developed before the adoption of the 2030 Agenda, and therefore do not correlate with the achievement of the SDG and require a substantial revision.

Creation of a long-term integrated strategy in the field of the civil service personnel policy of the Republic of Belarus, which will take into account the prospects of the country's innovative development, the approaches, and goals in the field of sustainable development that will be implemented, will allow us to work ahead of schedule. The existence of such a strategy will make it possible to develop medium-term development programs, to formulate appropriate strategies in the area of professional development of personnel for both the civil service in general and for specific regions and even individual public authorities.

The ability to forecast what kind of personnel and in what quantity will be claimed in public administration, not only in the short term but also in the future, will allow reconstructing the educational process. Besides, it would let us avoid the situation when the created educational programs are a form of reaction to the transformations that have already occurred.

The next step will be the introduction of changes in the system of planning the education of civil servants. Currently, the list of education profiles, areas of education, specialties is determined by the governmental order that is formed and approved annually.

In the conditions of modern tendencies and challenges, the current practice of forming a governmental order for a period of one year does not always make it possible to ensure a high professional level of civil servants. Regular, scientifically based planning of civil servants' education for a longer term will avoid the lack of systematic training of personnel, provide public authorities with employees whose level of training will allow solving not only current but also strategic tasks. This, in turn, will lead to an increase in the effectiveness of the public administration.

It is indisputable that the quality of education and the level of organization of the educational process depend not only on the content of legal acts regulating all the components of the process of forming the governmental order for the training of highly qualified personnel, but also on the educational programs and teaching materials used, the professionalism of the faculty, modern forms and methods of teaching.

The complex transformation of the framework of the civil servants' education is necessary in order to make it more efficient and effective. We believe that the successful achievement of the SDG is possible only if they are taken into account in the programs of the social and economic development of the Republic of Belarus, the tasks and functions of public authorities, the qualification requirements for the civil servants, and in the scientific and methodological support of the educational process. In the Republic of Belarus, the scientific and methodological support of the educational process includes curriculum, syllabus, textbooks, etc.

At the same time, we consider it necessary to move from the practice of retraining to 
lifelong learning. Retraining in Belarus means that a civil servant with a degree similar to the bachelor's degree in economics, law or another specialty continues to study under an abbreviated program with the assignment of a degree similar to the bachelor in public administration. Lifelong education will allow civil servants to take into account previous experience and, instead of retraining, go further - master's, postgraduate, or strengthen individual skills as part of an internship or advanced training.

No less significant is the expansion of the subject composition of the educational process. Active participants should be practitioners, foreign experts, and the students themselves. The fact that civil servants have cognitive needs and interests, internal promptings for their satisfaction, awareness of efforts and organization of actions will allow to achieve significant results. We believe that the predominance of interactive forms and methods of training (business games, discussions, brainstorming, project methods, etc.) in the system of professional development of public servants will help to gain the knowledge necessary to achieve the SDGs.

An actual need is to provide a practice-oriented approach in education, as well as internships, field visits, interdepartmental training. We believe that practical orientation and interdepartmental training allow strengthening the competence of civil servants in solving complex tasks taking into account various state interests instead of a departmental approach.

Finally, an integrated approach to the learning process can be largely achieved through the use of information and communication technologies. These technologies are needed both to improve the efficiency of the educational process and to strengthen the information literacy of public servants. H. A. Turner comes to the conclusion about the relationship between the values of public service, professionalism and information literacy. Information literacy helps make sure that a public servant is competent in using information to promote public interest (2015, p. 51). A. Ni Ya and Y. Chen believe that with the introduction of information technology in public administration, public servants need to be competent in their effective use (2016, p. 194). Information technology in public administration, among other things, can be used to involve the population in public affairs, which also makes it possible to contribute to sustainable development.

At present, there are 568 thousand disabled people in the republic, which is $5.98 \%$ of the population of the Republic of Belarus. Persons with disabilities in the Republic of Belarus have full political, socio-economic, personal rights and freedoms. Nevertheless, their legal status continues to be strengthened. The Republic of Belarus signed in 2015, and in 2016 ratified the Convention on the Rights of Persons with Disabilities. In order to ensure coordinated actions for the implementation of the Convention, the National Action Plan for the implementation in Belarus of the provisions of the Convention on the Rights of Persons with Disabilities for 2017-2025, which provides for changes in legislation, has been approved. In order to enhance the inclusiveness of public administration, we consider it expedient to more actively involve people with disabilities in public service. At the same time, the implementation of sustainable development goals in the conditions of digital transformation and e-government requires from individuals with special needs, as well as from the entire population, new knowledge, skills and abilities that allow to smoothly join the government. Issues regarding digital skills and soft skills of persons with special needs deserve special attention in new realities. The 
expansion of information literacy, the creation of conditions for their lifelong learning will enable them to actively participate in work, social life and governing the country in new conditions. The solution of these issues is seen in the organization at the UNESCO Chair on Vocational Education in the Sphere of Information and Communication Technologies (ICTs) of Persons with Special Needs at the Institute of Information Technologies of the Belarusian State University of Informatics and Radioelectronics together with other UNESCO Chairs in Belarus and other interested, including public associations persons with disabilities, work on the improvement of educational activities with the use of information technologies, scientific research, organization of scientific and other events.

In conclusion, we believe that the implementation of the SDG dictates a significant change in approaches to civil servants' education based on understanding the content and importance of the sustainable development paradigm.

\section{Acknowledgements}

We express our gratitude to the European Union funded project for enhancing professional contacts between Belarus and EU "Mobility Scheme for Targeted Peopleto-People -Contacts" for granting the possibility to take part in the 7 th International Conference on Sustainable Development.

\section{References}

Annan-Diab, F., \& Molinari, C. (2017). Interdisciplinarity: Practical approach to advancing education for sustainability and for the Sustainable Development Goals. The International Journal of Management Education, 15(2), 73-83.

Berceanu, B., \& Carausan, M. (2014). The Civil Service Reform in the Context of Sustainable Development: A Comparison Between Romania and Italy. Acta Universitatis Danubius. Administratio, 6(1), 26-40.

Fukukawa, K., Spicer, D., Burrows, S. A., \& Fairbrass, J. (2013). Sustainable Change: Education for Sustainable Development in the Business School. Journal of Corporate Citizenship. (49), 71-99.

Hailey, J. (1998). Management education for sustainable development. Sustainable Development, 6(1), 40-48.

Ni Ya, A., \& Chen, Y.-C. (2016). A Conceptual Model of Information Technology Competence for Public Managers: Designing Relevant MPA Curricula for Effective Public Service. Journal of Public Affairs Education, 22(2), 193-212.

Terlević, M., Istenič Starčič, A., \& Šubic Kovač, M. (2015). Sustainable spatial development in higher education. Urbani Izziv, 26(1), 105-120.

Turner, A. H. (2015). Instilling Public Service Values and Professionalism Through Information Literacy. Journal of Public Affairs Education, 21(1), 41-54.

Viertel, E. (2010). Vocational Education for Sustainable Development: an obligation for the European Training Foundation. European Journal of Education, 45(2), 217-235.

Rybasova, M. \& Razhabova, Z. (2014). The Role of the State in Ensuring the Sustainable Development of the Modern Economy. Scientific Institute of Global and Regional Economics. (4), 69-71. 